\title{
Oxidative Stress: a Promising Target for Chemoprevention
}

\author{
A. M. Sashi Papu John ${ }^{1}$ - Murali K. Ankem ${ }^{1} \cdot$ Chendil Damodaran $^{1}$
}

Published online: 5 February 2016

(C) Springer International Publishing AG 2016

\begin{abstract}
Cancer is a leading cause of death worldwide, and treating advanced stages of cancer remains clinically challenging. Epidemiological studies have shown that oxidants and free radicals induced DNA damage is one of the predominant causative factors for cancer pathogenesis. Hence, oxidants are attractive targets for chemoprevention as well as therapy. Dietary agents are known to exert an antioxidant property which is one of the most efficient preventive strategy in cancer progression. In this article, we highlight dietary agents can potentially target oxidative stress, in turn delaying, preventing, or treating cancer development. Some of these agents are currently in use in basic research, while some have been launched successfully into clinical trials.
\end{abstract}

Keywords Natural compounds $\cdot$ Anti-oxidants $\cdot$ Prevention Cancer

\section{Introduction}

Despite great advancements in understanding the etiology and the molecular mechanisms underlying disease progression, cancer remains a leading cause of death worldwide and in the USA. Oxidative stress is a predominant causative factor in cancer development. Both reactive oxygen species (ROS) and reactive nitrogen species (RNS), referred to as oxidants, are generated as byproducts of oxygen and nitrogen metabolism, respectively, in various normal metabolic pathways [1].

This article is part of the Topical Collection on Free Radicals Medicine

Chendil Damodaran

Chendil.damodaran@louisville.edu

1 Department of Urology, University of Louisville, Louisville, KY 40202, USA
Production of oxidants in normal cells are tightly governed by enzymes in a controlled manner regulating several signaling pathways and functions including cell division, inflammation, immune autophagy, and stress response [2]. Any imbalance between free radicals (ROS, RNS) and antioxidants is the underlying basis of oxidative stress.

Dietary agents and supplements are major sources of antioxidants and are solely aimed at protecting aerobic organisms from the toxic effects of free radicals and oxidants. Antioxidants neutralize oxidative stress, either enzymatically (vitamins $\mathrm{C}$ or $\mathrm{E}$ or $\beta$-carotene) or non-enzymatically (superoxide dismutase [SOD], catalase [CAT], or glutathione peroxidase) to protect the organelles. Several epidemiological studies have demonstrated that changes in lifestyle and dietary habits could prevent or reduce cancer incidence [3]. Therefore, this review article aims to highlight the potential roles of dietary agents exerting antioxidant properties that may impede cancer progression (Fig. 1).

\section{Molecular Function of Oxidative Stress}

Carcinogenesis is a process that includes transforming a normal cell into a cancerous cell. It is a multistep process broadly involving either an aberrant expression of proto-oncogenes or downregulation of tumor suppressor genes. Over decades, studies have shown that cancer cells produce elevated levels of superoxide or $\mathrm{H}_{2} \mathrm{O}_{2}$, leading to oxidative stress that significantly aids in the transformation of healthy cells to tumor cells. The molecular pathways involved in an oxidative response include PI3K/AKT, PKC, STATs, AP-1, Ras/Raf/ MAP kinase, ERK, NF- $\mathrm{KB}, \mathrm{Nrf} 2$, VEGF, and JNK signaling by regulating cell-cycle progression, survival, invasion, and metastasis of cancer cells (Table 1). These studies not only highlight the significance of ROS and free radicals in regulating cancer, but also delineate how ROS is targeted through various dietary agents. 
Fig. 1 Modulation of oxidative stress by dietary agents. Oxidative stress induced by increased ROS, RNS, or free radicals reduces antioxidant production, thus triggering tumor growth. Activation of antioxidants (Nrf2, NQO1, GCLM, HO-1, and MRP1) by dietary agents inhibits oxidative stress, impeding cancer progression

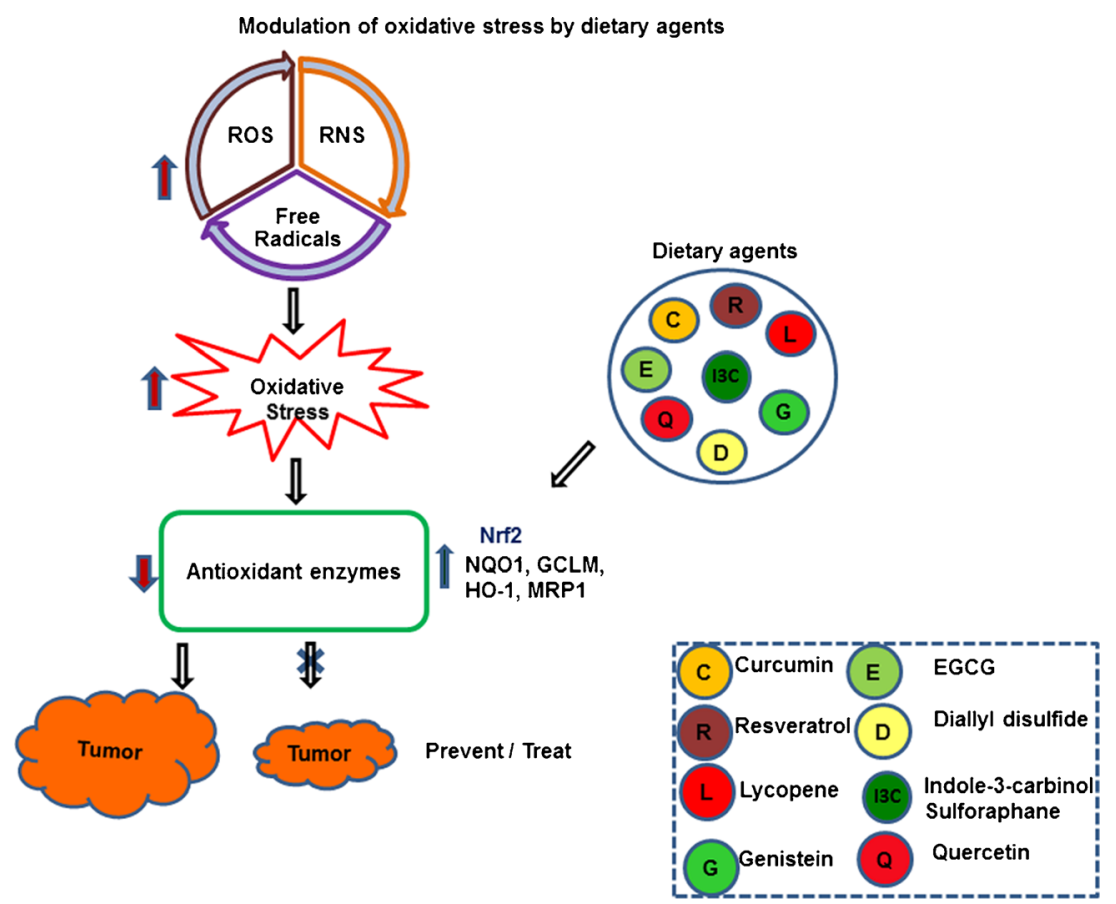

\section{Dietary Agents and Anticancer Effects}

It has been evidently proved beyond doubt that foods and dietary supplements are powerful sources of antioxidants and that regular consumption of both fruits and vegetables can either prevent or reduce cancer risk. Over decades, research has highlighted a promising approach in cancer research by tapping the enormous potential of many herbal sources of antioxidants in combating oxidative stress, thus targeting cancer.

\section{Curcumin}

The well-known pleiotropic effect of curcumin with curcuminoid, the yellow pigment (turmeric), has been well documented for its traditional medicinal properties against various human ailments in both Chinese and Indian systems of medicine since ancient times. As a naturally occurring polyphenol isolated from the rhizome of Curcuma longa, curcumin (turmeric) has gained popularity because of its safety, low cost, and abundance. Approved by the US Food and Drug Administration (FDA), studies have shown that consumption of curcumin is safe, even at higher doses, with no toxicity in animals [4] or humans [5]. The exceptional therapeutic potential of curcumin as an anti-inflammatory, antioxidant, hypoglycemic, anti-angiogenic, pro-apoptotic, and anticancer agent has been extensively studied. As an antiinflammatory agent, it inhibits production of NO and COX2 as well as NF-kB activation [6, 7]. It also scavenges ROS and decreases specificity protein transcription factors by targeting microRNAs [8]. The possible therapeutic effects of curcumin on several diseases are mainly associated with
Table 1 Dietary compounds and major molecular targets

\begin{tabular}{ll}
\hline Dietary compound(s) & Molecular targets \\
\hline Curcumin & NO, COX-2, NK-kB, MAPK, PI3K/AKT/Fox01/BRCA-1, H2AFX \\
& and PARP-1, hsp, Nrf2 \\
Resveratrol & NF-kB/Wnt/ 3 -catenin, Nrf2 \\
Lycopene & IGBPs/PDGF/VEGF PI3K/AKT/PKB, Ras/Raf/MAP, \\
& cyclin D, c-myc Bcl-2, Bcl-XL, ERK/AKT, NF-kB, Nrf2 \\
Epigallocatechin-3-gallate & Caspase activation, Bcl-2; NF-kB MAPK/TGF- $\beta$ /EGFR/JAK/STAT; \\
& PI3K/AKT, Wnt/Notch, Nrf2 \\
Quercetin & p53/ras protein/estrogen receptor/NF-kB, EGFR/PI3K/AKT/MAPKs; \\
& TRPM7, Nrf2 \\
Diallyl disulfide & MAPKs and NF-kB/PI3K/AKT; p53/p21 and MEK-ERK, Nrf2 \\
Genistein & NF-kB, VEGF, PDGF, EGF, IGF, JNK1, ERK/PI3K/AKT, Nrf2 \\
Indole-3-carbinol and sulforaphane & Nrf2/ARE/Wnt/3-catenin \\
\hline
\end{tabular}


inhibition of oxidative stress and its downstream mediators. Several studies have evidently shown that curcumin inhibits free radical formation [9], lipid peroxidation [10], DNA damage [11], and damage to cytochrome $\mathrm{p} 450$, but induces glutathione-S-transferase [12].

It is well documented that curcumin's anticancer properties make it feasible in preclinical trials to modulate multiple cellsignaling pathways through mitigation or prevention of many different types of cancers, including multiple myeloma, colorectal, pancreatic, breast, prostate, lung, head \& neck, in both animal models and humans [13]. In lung cancer, curcumin induces apoptosis accompanied by changes in intracellular oxidative stress-related enzymes and also by phosphorylation and activation of the mitogen-activated protein kinase signaling pathway factors c-Jun N-terminal kinase, p38, and extracellular signal-regulated kinase [14]. In pancreatic B cells, curcumin attenuates palmitate-induced apoptosis through $\mathrm{PI} 3 \mathrm{~K} / \mathrm{AKT} / \mathrm{Fox} 01$ and mitochondrial survival pathways [15]. A decrease in ROS with a concomitant increase in various antioxidant and DNA repair genes, such as BRCA-1, H2AFX, and PARP-1, were observed after curcumin treatment [9]. Studies have also shown that curcumin downregulates heat shock proteins and histone deacetylation in tumor cells under oxidative stress. It also induces apoptosis by modulating apoptosis-related proteins and also arrests the cell cycle by inhibiting tumor markers [16].

An approximate daily intake of 60-100 mg of curcumin in adults has been reported in the Indian diet [17]. Based on dietary intake, dosages as high as $12 \mathrm{~g}$ /day during the first 3 months of treatment are in phase I, II, and III clinical trials [18]. In several studies using curcumin on multiple molecular targets, it has been demonstrated that cancer therapy is limited because of curcumin's poor stability and bio-availability resulting from its increased oxidative degradation. However, a recent study has clearly shown that an encapsulation of curcumin as a redox nanoparticle rapidly scavenges the free radicals and ROS by overcoming the oxidative degradation, thus making it more potential than curcumin alone in cancer therapy [19].

\section{Resveratrol}

Phytoestrogens are phenolic compounds that are naturally occurring bioactive food components with diverse chemopreventive properties including antioxidant and angiogenic activities [20,21]. Of the various classes of phytoestrogens, resveratrol (trans-3,4',5-trihydroxystilbene), found in varying concentrations in many plants such as grapes, berries, and nuts, has evidently showed that it interferes at all the three stages of carcinogenesis (initiation, promotion, and progression). As a potent antioxidant, it plays a crucial role by regulating several antioxidant enzymes, including glutathione peroxidase, glutathione- $S$-transferase, and glutathione reductase [22]. It also prevents low density lipoprotein oxidation [23] and inhibits platelet aggregation [24].

While the effects of resveratrol on cancer are at this time uncertain, numerous studies have clearly highlighted its beneficial effects, such as cardiovascular and cancer preventive properties. In vitro findings in several labs have shown its anticancer effects in breast, skin, gastric, colon, esophageal, prostate, and pancreatic cancer as well as leukemia [25]. Activation of NF-KB due to changes in cytokine and ROS levels in various diseases, including cancer, has been decreased by resveratrol [26]. The anticancer properties of resveratrol include apoptotic induction by modulating the levels of Fas and FasL [27], reducing surviving expressions of both of these and $\mathrm{Wnt} / \beta$-catenin signaling pathways [28], and inhibiting angiogenesis [29]. Resveratrol's antioxidant activity prevents tumor formation resulting from DNA damage [30].

As a chemopreventive agent, resveratrol has a dual role; it is anti-apoptotic and pro-apoptotic, and these diverse health benefits are enabled in a dose-dependent manner. Low doses maintain protection from various types of diseases; however, higher doses have been shown to inhibit tumor growth [31]. It is rapidly absorbed and metabolized and is safe in long-term administration against several pathological conditions. Although many studies have highlighted the potential therapeutic effects of resveratrol on various diseases, including cancer, whether it targets both survival and apoptotic signaling pathways needs to be ascertained through clinical trials.

\section{Lycopene}

Lycopene is a naturally occurring carotenoid that gives red color to fruits and vegetables. Predominantly rich in tomatoes ( 0.9 to $92.7 \mathrm{mg} / 100 \mathrm{~g}$ ) and tomato-based products (51 to $59.7 \mathrm{mg} / 100 \mathrm{~g}$ ), more than $80 \%$ of total lycopene intake in the Western diet is through these sources.

Lycopene possesses significant antioxidant activity by quenching and inactivating the ROS [32]. Studies have shown that it prevents and reduces the risk of heart disease and several cancers including lung and prostate cancer [33, 34]. Both lycopene and its indirect effects play beneficial roles in preventing oxidative reactions that arise from the formation of nitrosamines [35]. It potentially targets the mechanisms involved in cell cycle arrest and apoptotic induction by abolishing growth factor receptor signaling pathways [36]. Studies have shown that it inhibits cancer cell growth by inhibiting ROS and by decreasing ERK expression [37].

A clinical trial involving a large population of prostate cancer patients undergoing radical prostatectomy with 4.2 years follow-up with lycopene supplementation have shown significantly smaller tumors [38]. Antioxidant properties and other signaling mechanisms of lycopene are primarily responsible for its therapeutic effects, targeting growth factors, 
signaling pathways, antioxidant response element (ARE) regulation, cell cycles, apoptosis, cell invasion, and metastasis [39]. Findings on ethanolic extract of lycopene have shown that it triggers induction of phase II detoxification enzymes by activating ARE and its transcription factor nuclear factor $E_{2}-$ related factor 2, thus enhancing its anti-tumorigenic effect [40].

Lycopene exerts its effects by regulating several growth factors and signaling pathways, including reduction of IGF-1 levels with enhanced IGBPs (breast, lung, colorectal, and prostate cancers) [41], PDGF [42], and VEGF [43]. At attainable concentrations, it modulates cancer progression by downregulating $\mathrm{PI} 3 \mathrm{~K} / \mathrm{AKT}$, and $\mathrm{PKB}$ and the kinase metabolic pathways of Ras, Raf, and MAP. It also targets the subsequent expression of genes involved in cell proliferation (cyclin D, Bcl-2, and Bcl-XL), cell cycles, apoptosis [44, 45], inflammation, angiogenesis, invasion, and metastasis [39]. Cell cycle progression is arrested by lycopene at phases $\mathrm{G}_{0} / \mathrm{G}_{1}$ and $\mathrm{S}$ by decreasing the expression of cyclin D and c-myc [46].

Many preclinical epidemiological studies have shown that lycopene at physiological concentrations arrests cell proliferation in gastric (ERK pathway), colon (AKT signaling), breast, and prostate (NF-KB) cancers [37], but further clinical trials are needed to explore all its potential therapeutic roles. Because of its free radical scavenging property, lycopene has been proven beyond doubt to be a natural potential antioxidant compound. Moreover, its multi-targeting effects allow it to remain a promising dietary agent for cancer therapy, attracting scientists for extensive research.

\section{Epigallocatechin-3-Gallate}

Epigallocatechin-3-gallate (EGCG), a polyphenol in green tea (Camellia sinensis) popularly consumed as a healthpromoting beverage around the world, is another significant phytochemical. As a powerful antioxidant, anti-inflammatory, and anti-proliferative compound, it is the most potent of all catechins.

In recent years, the potential effects of green tea have been intensively studied in animal models, in vitro, and in human studies against many pathological conditions. Induction of antioxidant enzymes and phase II metabolism by ECGC has been highlighted in both animal and human models [47]. To a greater extent, it can inhibit tumorigenesis in the stomach, lungs, liver, breast, and colon during all three stages of cancer through multiple signaling pathways. The compound ginseng, found in green tea, has a synergistic effect with anticancer drugs in arresting colon cancer cell proliferation. These polyphenols inhibit cancer cell survival via several growth factor receptors. It has been shown that ECGC induces apoptosis via ROS-dependent mechanism [5] and caspase activation with altered Bcl-2 family member expression, decreasing NF- $\mathrm{kB}$ kinase activity and therefore reducing nitric oxide production along with up- or downregulation of a number of enzymes involved in MAPK, oncogenes, and tumor suppressor genes [48]. Enhanced expression of the genes responsible for TGF- $\beta$ signaling, mediated by ROS, was evident following EGCG treatment [47]. Furthermore, several studies have proven that it also inhibits tumor growth mediated by multisignaling pathways - EGFR, JNK, STAT, PI3K/AKT, Wnt, or Notch [49].

Studies emanating from various groups have highlighted that to a greater extent, ECGC prevents metastatic properties in various cancers, such as skin, prostate, liver, lung, breast, pancreatic, and other cancers; however, further studies will elucidate the protective effects of green tea against cancer metastasis [50]. A few clinical trials have also clearly demonstrated the anti-tumorigenic property of ECGC, showing delayed cancer onset followed by lower recurrence rates in breast cancer patients (stages I and II) [51]. The efficacy of green tea extracts, both in ointment and capsule forms, has further confirmed that ECGC is effective in treating cervical lesions, a beneficial therapy for HPV patients [52]. These results clearly highlight that ECGC, used either alone or in synergistic treatment with other chemotherapy drugs, has greater potential in cancer prevention and therapy, and it also explains its demanding roles in both phase II and III clinical trials.

\section{Quercetin}

Of the known bioflavonoids, quercetin $\left(3,3^{\prime}, 4^{\prime}, 5,7\right.$ pentahydroxyflavone) has gained interest in research because of its several potential health effects as an anti-inflammatory, immune-modulator, anti-atherogenic, antioxidant, anti-hypertensive, and anti-toxic [53, 54]. Major plant sources of the flavonoid, a brilliant citron yellow pigment, include red onions, tomatoes (organic), honey, fruits, and leafy vegetables [54] with an average daily intake of $30 \mathrm{mg}$ in Western countries [55]. Various effects of quercetin in the presence of low and high levels of reduced GSH have been clearly demonstrated to possess both antioxidant (low) and pro-oxidant (high) properties [56].

Quercetin, either alone or in combination, has significant anticancer effects by inducing cell death through apoptosis in leukemia, lung, hepatoma, oral, and colon cancer cell lines [57-62], inducing the apoptotic pathway, downregulating mutant $\mathrm{p} 53$, inhibiting the ras protein, and targeting estrogen receptor binding capacity [54]. The molecular mechanisms by which it exerts its therapeutic effects include inhibition of NF-KB [63] and EGFR [64], thus modulating the downstream $\mathrm{PI} 3 \mathrm{~K} / \mathrm{AKT}$ pathway. Apoptotic induction is also evinced by the action of quercetin inhibiting MAPKs and transient receptor potential melastatin 7 (TRPM7) channels in gastric tumors [65] and regulating Bcl-2 and Bax in breast cancers [66]. A recent study has revealed that it also reverses tamoxifen resistance in breast cancer cells [67]. Another important mechanism is its ability to modulate estrogen receptors, thus 
inducing apoptosis, which is ER $\alpha$-dependent. Furthermore, it renders a protective dual role against E2-related cancers, especially in $\mathrm{ER} \alpha$ - and $\mathrm{ER} \beta$-expressing organs [68].

As a well-known therapeutic dietary agent, quercetin also regulates cell cycle progression, targeting several factors, including p21, cyclin B, p27, CDK, and topoisomerase II, thus inducing cell cycle arrest either at the $\mathrm{G}_{2} / \mathrm{M}$ or $\mathrm{G}_{1} / \mathrm{S}$ stages or a location specific to tumor origin [69]. Recent studies have evidently shown that it reduces the production of hyperalgesic cytokines and oxidative stress and also activates the opioiddependent analgesic pathway, thus making it a most relevant therapeutic option in treating cancer-associated pain [70]. However, further investigation is recommended. Its poor solubility in water is a hurdle which is improvised by combining it with either (polyethylene glycol) [71] or sulfobutyl ether7 beta-cyclodextrin, augmenting its anticancer effects. The above mentioned beneficial effects of quercetin makes it a potential cancer therapy.

\section{Diallyl Disulfide}

Diallyl disulfide (DADS; 4,5-dithia-1,7-octadiene), is a major organosulphur compound present in garlic and few allium plants. Recent studies have shown that the natural compound, allicin, has significant anti-mitotic effects both in vivo [72] and in vitro [73]. It has been shown that DADS scavenges free radicals and oxidants by stimulating the activities of GPX, glutathione reductase, and SOD [74].

Diallyl disulfide prevents hemorrhagic cystitis by inhibiting oxidative damage and the MAPKs and NF- $\mathrm{KB}$ pathways [75]. Possible protective antioxidant mechanisms are explained by various authors and include activation of $\mathrm{Nrf} 2$ pathways by inhibition of NF-KB activation, thus preventing hepatotoxicity [76]. Koh et al. reported the dose-dependent role of DADS on PC-12 cells, resulting in a neuroprotective effect at lower concentrations by activating PI3K and AKT and inhibiting GSK-3 activation, cytochrome-c release, caspase 3 activities, and PARP cleavage while it is cytotoxic at higher concentrations [77].

As an effective anticancer agent, DADS inhibits growth and the metastatic potentials of various cancers, such as breast, gastric, leukemia, esophageal, squamous cell carcinoma, prostate, colorectal adenoma, uterine, lung, and skin cancers [78-80]. Epidemiologic studies have undoubtedly shown that the frequency of contracting gastric cancer is significantly reduced with increased consumption of garlic [81]. Studies have also shown that it reduces PSA, a well-known prostate cancer biomarker [82]. Induction of apoptosis is related to the anti-proliferative effect of DADS mediated through the signaling pathways of EGFR, ERK, and PKM2 [49], p53, p21, and MEK-ERK [62], and also by inducing cell cycle arrest.
These studies clearly show the multi-tasking effect of these organosulfur compounds. DADS as a potent thearapeutic agent, modulates the cellular redox state, detoxifies carcinogens, inducing cell cycle arrest, apoptosis and inhibit angiogenesis with minimal toxic effects on healthy cells. Most in vivo and in vitro studies have used this compound at higher concentrations; therefore, the feasibility of using such high concentrations in human clinical trials needs to be reviewed before it can be used for prevention or treatment of cancer.

\section{Genistein}

The predominant food sources of the phytoestrogens genistein and daidzein are soybeans and their by-products, lupin, chick peas, and other legumes. Present as $\beta$ glucoside, genistein is an isoflavone that exhibits antioxidant, anti-proliferative, and anti-carcinogenic properties, and it is more potent than daidzein. The antioxidant and anticancer effects as well as other pharmacological properties of genistein are brought about by free genistein aglycone, found after digestion of the glycosylated form of genistein in the small intestine [83]. As a potent antioxidant, genistein induces the antioxidant enzymes such as glutathione peroxidase, SOD, and glutathione reductase, which ehances the free radicals scanvenging and decreases lipid peroixiation [84].

Several studies have clearly proven the differential effect of genistein as an estrogenic and anti-estrogenic, attributing to the treatment of hormone-related cancers [85]. The average daily dietary intake of isoflavones are comparatively lower in Western countries (2 $\mathrm{mg}$ ) than in Asian countries $(25-50 \mathrm{mg})$ [86, 87], a causative factor of disparity observed in the frequency of breast and prostate cancers. Soybeans modulate carcinogenesis by targeting tumor initiation, proliferation, and progression. Genistein augments its anticancer properties through downregulating several molecular pathways-NF-kB, VEGF, PDGF, EGF, IGF, JNK1, ERK/PI3K/AKT [88]. In vivo and in vitro studies have proven the efficacy and synergistic effects of genistein in inhibiting cell proliferation and inducing apoptosis in liver, lung, colon, and prostate cancers [89-92]. Based on epidemiological data, the role of isoflavone in gastric cancer is debatable because schools of thought differ $[77,93]$. The paradoxical effect of genistein is that it has an anti-tumorigenic effect at higher concentrations $(>10 \mathrm{uM})$ in both estrogen receptor-positive and -negative breast cancer cells; however, at lower concentrations, it stimulates the proliferation of ER-positive breast cancer cell lines [94].

As a FDA-approved drug and in phase I and II trials for the treatment of metastatic colorectal cancer, genistein has gained more importance [95]. Although variations occur between the 
epidemiologic in vitro and in vivo studies, more research and additional clinical trials are required to validate genistein as a potent anticancer drug. Nonetheless, it has thus far been shown to exert chemo-preventive effects and therefore is a promising anticancer agent.

\section{Indole-3-Carbinol and Sulforaphane}

Another natural compound, predominantly found in members of the Brassica genus (cabbage, radishes, cauliflower, broccoli, sprouts, and daikon), is glucosinolate. After consumption of glucosinolate, the active organosulfur compounds indole-3-carbinol (I3C) and sulforaphane, which possess anticancer properties, are formed. Both the phytochemicals have potent antioxidant, anti-carcinogenic, and anti-atherogenic properties; however, they increased the expression of genes encoding antioxidant enzymes (CAT, SOD, GR, and GPX) in hepatoma cells through Nrf2 and ARE signaling pathways [96]. Findings have also shown that the anti-tumorigenic effect of I3C is partly achieved by one of its major byproducts, diindolylmethane, which acts as an anti-angiogenic, inducing cell death.

Highlighting the anti-tumorigenic properties, both in vivo and in vitro studies have showed that $\mathrm{I} 3 \mathrm{C}$ arrests the $\mathrm{G}_{1}$ cell cycle and inhibits the growth of breast cancer cells through degradation of Cdc25A [97]. Numerous in vitro, in vivo, and human studies have shown its targeted ability to suppress cell proliferation in various cancer models (breast [98], prostate [99], colon [100], lung [101], and leukemia [102]). However, most therapeutic studies reveal that $\mathrm{I} 3 \mathrm{C}$ is more potent for hormonaldependent cancers such as breast and cervical cancer under in vivo conditions. Further studies have shown sulforaphane as a potent inducer of phase II detoxication enzymes [103], and $\mathrm{I} 3 \mathrm{C}$ reversed the cytotoxic effect of dexamethasone by blocking ROS overproduction and Nrf2 expression enhancement [104]. Sulforaphane also has a therapeutic role in neurodegenerative disorders other than cancer (Wnt and $\beta$-catenin).

This clearly underscores the potential use of these organosulfur compounds as therapeutic agents against cancer and other diseases mediated through suppression of free radical production, induction of apoptosis, and regulation of various signaling pathways.

\section{Conclusion}

Studies have clearly shown that both lifestyle and types of dietary intake have a significant influence on preventing the cancer incidence by activating anti-inflammatory pathways. The rapid increase in cancer research over the decades has shed some light on identifying and targeting the molecular pathways in cancer treatment. With the availability of many therapeutic methods aiming toward cancer treatment, chemoprevention by potent dietary agents is of greater significance as it targets many signaling pathways. The studies highlight the importance of antioxidants as one of the potential tool in cancer prevention and treatment by scavenging the effects of free radicals and oxidants. Treatment with these dietary agents rich in antioxidants, either alone or in combination, focuses the beneficial effects of inhibiting cell proliferation, survival, invasion, and metastasis and inducing apoptosis. It may be noteworthy, that this article emphasizes only some of the predominant dietary compounds, although there are still a larger number compounds that are being explored. However, because of the differential effects of some of these compounds, further exploration is needed. It is highly imperative to have a better understanding of the possible roles of these compounds so that they can be used in safe and effective cancer therapies. Nevertheless, consumption of dietary agents and their byproducts can help prevent cancer.

AKT/PKC, Protein kinase C; AP-1, Activator Protein 1; ARE, Antioxidant response element; Bax, BCL2-associated $\mathrm{X}$ protein; Bcl-2, B cell lymphoma 2; Bcl-xl, B cell lymphoma-extra-large; BRCA-1, Breast cancer 1; CAT, Catalase; Cdc25A, Cell Division Cycle 25A; CDK, Cyclindependent kinase; COX-2, Cyclooxygenase; EGFR, epidermal growth factor receptor; Fas, cell-surface Fas receptor; FasL, Fas ligand; Fox01, Forkhead box protein O1; GPx, glutathione peroxidase; GR, glutathione reductase; GSH, Glutathione; GSK-3, Glycogen Synthase Kinase 3; H2AFX, H2A histone family; IGBP, IGF binding protein; IGF-1, Insulin-like Growth Factor-1; JNK, Janus kinase; NF-kB, Nuclear factor-kappa B; NO, Nitric oxide; Nrf-2, Nuclear factor erythroid 2 [NF-E2]-related factor 2; PARP-1-, (Poly (ADP-Ribose) Polymerase 1; PDGF, Platelet-derived growth factor; PI3K, Phosphoinositide 3-kinase; PSA, Prostate specific antigen; Ras/Raf/MAP, kinase; ERK, Mitogen-activated protein kinase; SOD, Superoxide dismutase; STATs, Signal transducer and activator of transcription; TGF- $\beta$, Transforming growth factor-beta; VEGF, Vascular endothelial growth factor; Wnt, Wingless signaling in Drosophila

Acknowledgments This work was supported by R01CA140605 and R01CA138797.

\section{Compliance with Ethical Standards}

Conflict of Interest None.

Human and Animal Rights and Informed Consent This article does not contain any studies with human or animal subjects performed by any of the authors. 


\section{References}

1. Wolfle U, Seelinger G, Bauer G, Meinke MC, Lademann J, Schempp CM. Reactive molecule species and antioxidative mechanisms in normal skin and skin aging. Skin Pharmacol Physiol. 2014;27(6):316-32.

2. Finkel T. Signal transduction by reactive oxygen species. J Cell Biol. 2011;194(1):7-15.

3. Anand P, Kunnumakkara AB, Sundaram C, Harikumar KB, Tharakan ST, Lai OS, et al. Cancer is a preventable disease that requires major lifestyle changes. Pharm Res. 2008;25(9):2097116.

4. Sridhar R, Ravanan S, Venugopal JR, Sundarrajan S, Pliszka D, Sivasubramanian $\mathrm{S}$, et al. Curcumin- and natural extract-loaded nanofibres for potential treatment of lung and breast cancer: in vitro efficacy evaluation. J Biomater Sci Polym Ed. 2014;25(10):985-98

5. Lao CD, Ruffin MT, Normolle D, Heath DD, Murray SI, Bailey $\mathrm{JM}$, et al. Dose escalation of a curcuminoid formulation. BMC Complement Altern Med. 2006;6:10.

6. Bhaumik S, Jyothi MD, Khar A. Differential modulation of nitric oxide production by curcumin in host macrophages and NK cells. FEBS Lett. 2000;483(1):78-82.

7. Surh YJ, Chun KS, Cha HH, Han SS, Keum YS, Park KK, et al. Molecular mechanisms underlying chemopreventive activities of anti-inflammatory phytochemicals: down-regulation of COX-2 and iNOS through suppression of NF-kappa B activation. Mutat Res. 2001;480-481:243-68.

8. Gandhy SU, Kim K, Larsen L, Rosengren RJ, Safe S. Curcumin and synthetic analogs induce reactive oxygen species and decreases specificity protein $(\mathrm{Sp})$ transcription factors by targeting microRNAs. BMC Cancer. 2012;12:564.

9. Jain A, Samykutty A, Jackson C, Browning D, Bollag WB, Thangaraju M, et al. Curcumin inhibits PhIP induced cytotoxicity in breast epithelial cells through multiple molecular targets. Cancer Lett. 2015;365(1):122-31.

10. Al-Rubaei ZM, Mohammad TU, Ali LK. Effects of local curcumin on oxidative stress and total antioxidant capacity in vivo study. Pak J Biol Sci. 2014;17(12):1237-41.

11. Tokac M, Taner G, Aydin S, Ozkardes AB, Dundar HZ, Taslipinar MY, et al. Protective effects of curcumin against oxidative stress parameters and DNA damage in the livers and kidneys of rats with biliary obstruction. Food Chem Toxicol. 2013;61:28-35.

12. Koe XF, Tengku Muhammad TS, Chong AS, Wahab HA, Tan ML. Cytochrome P450 induction properties of food and herbalderived compounds using a novel multiplex RT-qPCR in vitro assay, a drug-food interaction prediction tool. Food Sci Nutr. 2014;2(5):500-20.

13. Devassy JG, Nwachukwu ID, Jones PJ. Curcumin and cancer: barriers to obtaining a health claim. Nutr Rev. 2015;73(3):155-65.

14. Yao Q, Lin M, Wang Y, Lai Y, Hu J, Fu T, et al. Curcumin induces the apoptosis of A549 cells via oxidative stress and MAPK signaling pathways. Int J Mol Med. 2015;36(4):1118-26. doi:10. 3892/ijmm.2015.2327.

15. Hao F, Kang J, Cao Y, Fan S, Yang H, An Y et al. Curcumin attenuates palmitate-induced apoptosis in MIN6 pancreatic betacells through $\mathrm{PI} 3 \mathrm{~K} / \mathrm{Akt} / \mathrm{FoxO} 1$ and mitochondrial survival pathways. Apoptosis. 2015.

16. Sarkar R, Mukherjee A, Mukherjee S, Biswas R, Biswas J, Roy M. Curcumin augments the efficacy of antitumor drugs used in leukemia by modulation of heat shock proteins via HDAC6. J Environ Pathol Toxicol Oncol. 2014;33(3):247-63.

17. Tayyem RF, Heath DD, Al-Delaimy WK, Rock CL. Curcumin content of turmeric and curry powders. Nutr Cancer. 2006;55(2): $126-31$
18. Dhillon N, Aggarwal BB, Newman RA, Wolff RA, Kunnumakkara AB, Abbruzzese JL, et al. Phase II trial of curcumin in patients with advanced pancreatic cancer. Clin Cancer Res. 2008;14(14):4491-9.

19. Thangavel S, Yoshitomi T, Sakharkar MK, Nagasaki Y. Redox nanoparticles inhibit curcumin oxidative degradation and enhance its therapeutic effect on prostate cancer. J Control Release. 2015;209:110-9.

20. Cao Y, Fu ZD, Wang F, Liu HY, Han R. Anti-angiogenic activity of resveratrol, a natural compound from medicinal plants. J Asian Nat Prod Res. 2005;7(3):205-13.

21. Siddiqui IA, Sanna V, Ahmad N, Sechi M, Mukhtar H. Resveratrol nanoformulation for cancer prevention and therapy. Ann N Y Acad Sci. 2015;1348(1):20-31.

22. Yen GC, Duh PD, Lin CW. Effects of resveratrol and 4hexylresorcinol on hydrogen peroxide-induced oxidative DNA damage in human lymphocytes. Free Radic Res. 2003;37(5):509-14.

23. Frankel EN, Waterhouse AL, Kinsella JE. Inhibition of human LDL oxidation by resveratrol. Lancet. 1993;341(8852):1103-4.

24. Olas B, Wachowicz B, Szewczuk J, Saluk-Juszczak J, Kaca W. The effect of resveratrol on the platelet secretory process induced by endotoxin and thrombin. Microbios. 2001;105(410):7-13.

25. Gali-Muhtasib H, Hmadi R, Kareh M, Tohme R, Darwiche N. Cell death mechanisms of plant-derived anticancer drugs: beyond apoptosis. Apoptosis. 2015;20(12):1531-62.

26. Feitelson MA, Arzumanyan A, Kulathinal RJ, Blain SW, Holcombe RF, Mahajna J, et al. Sustained proliferation in cancer: mechanisms and novel therapeutic targets. Semin Cancer Biol. 2015;12(35 Suppl):S25-54.

27. Gu S, Chen C, Jiang X, Zhang Z. Resveratrol synergistically triggers apoptotic cell death with arsenic trioxide via oxidative stress in human lung adenocarcinoma A549 cells. Biol Trace Elem Res. 2015;163(1-2):112-23.

28. Fukada K, Takahashi-Yanaga F, Sakoguchi-Okada N, Shiraishi F, Miwa Y, Morimoto S, et al. Celecoxib induces apoptosis by inhibiting the expression of survivin in HeLa cells. Biochem Biophys Res Commun. 2007;357(4):1166-71.

29. Garvin S, Ollinger K, Dabrosin C. Resveratrol induces apoptosis and inhibits angiogenesis in human breast cancer xenografts in vivo. Cancer Lett. 2006;231(1):113-22.

30. Kalra N, Roy P, Prasad S, Shukla Y. Resveratrol induces apoptosis involving mitochondrial pathways in mouse skin tumorigenesis. Life Sci. 2008;82(7-8):348-58

31. Mukherjee S, Dudley JI, Das DK. Dose-dependency of resveratrol in providing health benefits. Dose Response. 2010;8(4):478-500.

32. Guder A, Korkmaz H, Gokce H, Alpaslan YB, Alpaslan G. Isolation, characterization, spectroscopic properties and quantum chemical computations of an important phytoalexin resveratrol as antioxidant component from Vitis labrusca L. and their chemical compositions. Spectrochim Acta A Mol Biomol Spectrosc. 2014;133:378-95.

33. Arab L, Steck S. Lycopene and cardiovascular disease. Am J Clin Nutr. 2000;71(6 Suppl):1691S-5S. discussion 6S-7S.

34. Kim MJ, Kim H. Anticancer effect of lycopene in gastric carcinogenesis. J Cancer Prev. 2015;20(2):92-6.

35. Yegin SC, Yur F, Cetin S, Guder A. Effect of lycopene on serum nitrite-nitrate levels in diabetic rats. Indian J Pharm Sci. 2015;77(3):357-60.

36. Rao AV, Ray MR, Rao LG. Lycopene. Adv Food Nutr Res. 2006;51:99-164.

37. Palozza P, Colangelo M, Simone R, Catalano A, Boninsegna A, Lanza P, et al. Lycopene induces cell growth inhibition by altering mevalonate pathway and Ras signaling in cancer cell lines. Carcinogenesis. 2010;31(10):1813-21.

38. Kirsh VA, Mayne ST, Peters U, Chatterjee N, Leitzmann MF, Dixon LB, et al. A prospective study of lycopene and tomato 
product intake and risk of prostate cancer. Cancer Epidemiol Biomarkers Prev. 2006;15(1):92-8.

39. Trejo-Solis C, Pedraza-Chaverri J, Torres-Ramos M, JimenezFarfan D, Cruz Salgado A, Serrano-Garcia N, et al. Multiple molecular and cellular mechanisms of action of lycopene in cancer inhibition. Evid Based Complement Alternat Med. 2013;2013: 705121.

40. Ben-Dor A, Steiner M, Gheber L, Danilenko M, Dubi N, Linnewiel $\mathrm{K}$, et al. Carotenoids activate the antioxidant response element transcription system. Mol Cancer Ther. 2005;4(1):177-86.

41. Giovannucci E, Rimm EB, Ascherio A, Stampfer MJ, Colditz GA, Willett WC. Alcohol, low-methionine-low-folate diets, and risk of colon cancer in men. J Natl Cancer Inst. 1995;87(4):265-73.

42. Chan CM, Fang JY, Lin HH, Yang CY, Hung CF. Lycopene inhibits PDGF-BB-induced retinal pigment epithelial cell migration by suppression of PI3K/Akt and MAPK pathways. Biochem Biophys Res Commun. 2009;388(1):172-6.

43. Chen ML, Lin YH, Yang CM, Hu ML. Lycopene inhibits angiogenesis both in vitro and in vivo by inhibiting MMP-2/uPA system through VEGFR2-mediated PI3K-Akt and ERK/p38 signaling pathways. Mol Nutr Food Res. 2012;56(6):889-99.

44. Kolberg M, Pedersen S, Bastani NE, Carlsen H, Blomhoff R, Paur I. Tomato paste alters NF-kappaB and cancer-related mRNA expression in prostate cancer cells, xenografts, and xenograft microenvironment. Nutr Cancer. 2015;67(2):305-15.

45. Rotelli MT, Bocale D, De Fazio M, Ancona P, Scalera I, Memeo $\mathrm{R}$, et al. IN-VITRO evidence for the protective properties of the main components of the Mediterranean diet against colorectal cancer: a systematic review. Surg Oncol. 2015;24(3):145-52.

46. Ono M, Takeshima M, Nakano S. Mechanism of the anticancer effect of lycopene (tetraterpenoids). Enzymes. 2015;37:139-66.

47. Lambert JD, Elias RJ. The antioxidant and pro-oxidant activities of green tea polyphenols: a role in cancer prevention. Arch Biochem Biophys. 2010;501(1):65-72.

48. Beltz LA, Bayer DK, Moss AL, Simet IM. Mechanisms of cancer prevention by green and black tea polyphenols. Anticancer Agents Med Chem. 2006;6(5):389-406.

49. Ma YC, Li C, Gao F, Xu Y, Jiang ZB, Liu JX, et al. Epigallocatechin gallate inhibits the growth of human lung cancer by directly targeting the EGFR signaling pathway. Oncol Rep. 2014;31(3):1343-9.

50. Khan N, Mukhtar H. Cancer and metastasis: prevention and treatment by green tea. Cancer Metastasis Rev. 2010;29(3):435-45.

51. Fujiki H, Suganuma M, Okabe S, Sueoka E, Suga K, Imai K, et al. Mechanistic findings of green tea as cancer preventive for humans. Proc Soc Exp Biol Med. 1999;220(4):225-8.

52. Erdogan E. Intraoral radiography with a new apparatus. Istanbul Univ Dishekim Fak Derg. 1972;3(3):337-57.

53. Boersma MG, van der Woude H, Bogaards J, Boeren S, Vervoort $\mathrm{J}$, Cnubben NH, et al. Regioselectivity of phase II metabolism of luteolin and quercetin by UDP-glucuronosyl transferases. Chem Res Toxicol. 2002;15(5):662-70.

54. Rani N, Velan LP, Vijaykumar S, Arunachalam A. An insight into the potentially old-wonder molecule-quercetin: the perspectives in foresee. Chin J Integr Med. 2015. doi:10.1007/s11655-015-2073-x.

55. Noroozi M, Burns J, Crozier A, Kelly IE, Lean ME. Prediction of dietary flavonol consumption from fasting plasma concentration or urinary excretion. Eur J Clin Nutr. 2000;54(2):143-9.

56. Robaszkiewicz A, Balcerczyk A, Bartosz G. Antioxidative and prooxidative effects of quercetin on A549 cells. Cell Biol Int. 2007;31(10):1245-50.

57. Atashpour S, Fouladdel S, Movahhed TK, Barzegar E, Ghahremani MH, Ostad SN, et al. Quercetin induces cell cycle arrest and apoptosis in CD133(+) cancer stem cells of human colorectal HT29 cancer cell line and enhances anticancer effects of doxorubicin. Iran J Basic Med Sci. 2015;18(7):635-43.
58. Lee WJ, Hsiao M, Chang JL, Yang SF, Tseng TH, Cheng CW, et al. Quercetin induces mitochondrial-derived apoptosis via reactive oxygen species-mediated ERK activation in HL-60 leukemia cells and xenograft. Arch Toxicol. 2015;89(7):1103-17.

59. Liu Y, Wu YM, Zhang PY. Protective effects of curcumin and quercetin during benzo(a)pyrene induced lung carcinogenesis in mice. Eur Rev Med Pharmacol Sci. 2015;19(9):1736-43.

60. Maurya AK, Vinayak M. Anticarcinogenic action of quercetin by downregulation of phosphatidylinositol 3-kinase (PI3K) and protein kinase $\mathrm{C}$ (PKC) via induction of p53 in hepatocellular carcinoma (HepG2) cell line. Mol Biol Rep. 2015;42(9):1419-29.

61. Refolo MG, D’Alessandro R, Malerba N, Laezza C, Bifulco M, Messa C, et al. Anti proliferative and pro apoptotic effects of flavonoid quercetin are mediated by CB1 receptor in human colon cancer cell lines. J Cell Physiol. 2015;230(12):2973-80.

62. Yuan Z, Wang H, Hu Z, Huang Y, Yao F, Sun S, et al. Quercetin inhibits proliferation and drug resistance in $\mathrm{KB} / \mathrm{VCR}$ oral cancer cells and enhances its sensitivity to vincristine. Nutr Cancer. 2015;67(1):126-36.

63. Zheng NG, Wang JL, Yang SL, Wu JL. Aberrant epigenetic alteration in Eca9706 cells modulated by nanoliposomal quercetin combined with butyrate mediated via epigenetic-NF-kappaB signaling. Asian Pac J Cancer Prev. 2014;15(11):4539-43.

64. Fridrich D, Teller N, Esselen M, Pahlke G, Marko D. Comparison of delphinidin, quercetin and (-)-epigallocatechin-3-gallate as inhibitors of the EGFR and the ErbB2 receptor phosphorylation. Mol Nutr Food Res. 2008;52(7):815-22.

65. Kim MC, Lee HJ, Lim B, Ha KT, Kim SY, So I, et al. Quercetin induces apoptosis by inhibiting MAPKs and TRPM7 channels in AGS cells. Int J Mol Med. 2014;33(6):1657-63.

66. Duo J, Ying GG, Wang GW, Zhang L. Quercetin inhibits human breast cancer cell proliferation and induces apoptosis via Bcl-2 and Bax regulation. Mol Med Rep. 2012;5(6):1453-6.

67. Wang H, Tao L, Qi K, Zhang H, Feng D, Wei W, et al. Quercetin reverses tamoxifen resistance in breast cancer cells. J BUON. 2015;20(3):707-13.

68. Bulzomi P, Galluzzo P, Bolli A, Leone S, Acconcia F, Marino M. The pro-apoptotic effect of quercetin in cancer cell lines requires ERbeta-dependent signals. J Cell Physiol. 2012;227(5):1891-8.

69. Gibellini L, Pinti M, Nasi M, Montagna JP, De Biasi S, Roat E, et al. Quercetin and cancer chemoprevention. Evid Based Complement Alternat Med. 2011;2011:591356.

70. Calixto-Campos C, Correa MP, Carvalho TT, Zarpelon AC, Hohmann MS, Rossaneis AC, et al. Quercetin reduces Ehrlich tumor-induced cancer pain in mice. Anal Cell Pathol (Amst). 2015;2015:285708.

71. Yuan ZP, Chen LJ, Fan LY, Tang MH, Yang GL, Yang HS, et al. Liposomal quercetin efficiently suppresses growth of solid tumors in murine models. Clin Cancer Res. 2006;12(10):3193-9.

72. Milner JA. Preclinical perspectives on garlic and cancer. J Nutr. 2006;136(3 Suppl):827S-31S.

73. Huang Z, Lei X, Zhong M, Zhu B, Tang S, Liao D. Bcl-2 small interfering RNA sensitizes cisplatin-resistant human lung adenocarcinoma A549/DDP cell to cisplatin and diallyl disulfide. Acta Biochim Biophys Sin (Shanghai). 2007;39(11):835-43.

74. Yin X, Zhang R, Feng C, Zhang J, Liu D, Xu K, et al. Diallyl disulfide induces $\mathrm{G} 2 / \mathrm{M}$ arrest and promotes apoptosis through the p53/p21 and MEK-ERK pathways in human esophageal squamous cell carcinoma. Oncol Rep. 2014;32(4):1748-56.

75. Kim SH, Lee IC, Ko JW, Moon C, Kim SH, Shin IS, et al. Diallyl disulfide prevents cyclophosphamide-induced hemorrhagic cystitis in rats through the inhibition of oxidative damage, MAPKs, and NF-kappaB pathways. Biomol Ther (Seoul). 2015;23(2):180-8.

76. Lee IC, Kim SH, Baek HS, Moon C, Kang SS, Kim SH, et al. The involvement of Nrf2 in the protective effects of diallyl disulfide on carbon tetrachloride-induced hepatic oxidative damage and 
inflammatory response in rats. Food Chem Toxicol. 2014;63:17485.

77. Koh SH, Kwon H, Park KH, Ko JK, Kim JH, Hwang MS, et al. Protective effect of diallyl disulfide on oxidative stress-injured neuronally differentiated PC12 cells. Brain Res Mol Brain Res. 2005;133(2):176-86.

78. Lin YT, Yang JS, Lin SY, Tan TW, Ho CC, Hsia TC, et al. Diallyl disulfide (DADS) induces apoptosis in human cervical cancer Ca Ski cells via reactive oxygen species and $\mathrm{Ca} 2+-$ dependent mitochondria-dependent pathway. Anticancer Res. 2008;28(5A): 2791-9.

79. Lu HF, Sue CC, Yu CS, Chen SC, Chen GW, Chung JG. Diallyl disulfide (DADS) induced apoptosis undergo caspase-3 activity in human bladder cancer T24 cells. Food Chem Toxicol. 2004;42(10):1543-52.

80. Nagaraj NS, Anilakumar KR, Singh OV. Diallyl disulfide causes caspase-dependent apoptosis in human cancer cells through a Bax-triggered mitochondrial pathway. J Nutr Biochem. 2010;21(5):405-12.

81. Yi L, Su Q. Molecular mechanisms for the anti-cancer effects of diallyl disulfide. Food Chem Toxicol. 2013;57:362-70.

82. Gunadharini DN, Arunkumar A, Krishnamoorthy G, Muthuvel R, Vijayababu MR, Kanagaraj P, et al. Antiproliferative effect of diallyl disulfide (DADS) on prostate cancer cell line LNCaP. Cell Biochem Funct. 2006;24(5):407-12.

83. Polkowski K, Popiolkiewicz J, Krzeczynski P, Ramza J, Pucko W, Zegrocka-Stendel O, et al. Cytostatic and cytotoxic activity of synthetic genistein glycosides against human cancer cell lines. Cancer Lett. 2004;203(1):59-69.

84. Wei YK, Gamra I, Davenport A, Lester R, Zhao L, Wei Y. Genistein induces cytochrome P450 1B1 gene expression and cell proliferation in human breast cancer MCF-7 cells. J Environ Pathol Toxicol Oncol. 2015;34(2):153-9.

85. Banerjee S, Li Y, Wang Z, Sarkar FH. Multi-targeted therapy of cancer by genistein. Cancer Lett. 2008;269(2):226-42.

86. Messina M, McCaskill-Stevens W, Lampe JW. Addressing the soy and breast cancer relationship: review, commentary, and workshop proceedings. J Natl Cancer Inst. 2006;98(18):1275-84.

87. van Erp-Baart MA, Brants HA, Kiely M, Mulligan A, Turrini A, Sermoneta C, et al. Isoflavone intake in four different European countries: the VENUS approach. Br J Nutr. 2003;89 Suppl 1:S2530 .

88. Varinska L, Gal P, Mojzisova G, Mirossay L, Mojzis J. Soy and breast cancer: focus on angiogenesis. Int J Mol Sci. 2015;16(5): $11728-49$.

89. Ito S, Igishi T, Takata M, Ueda Y, Matsumoto S, Kodani M, et al. Synergistic cell growth inhibition by the combination of amrubicin and Akt-suppressing agents in K-ras mutation-harboring lung adenocarcinoma cells: implication of EGFR tyrosine kinase inhibitors. Int J Oncol. 2014;44(3):685-92.

90. Kim EJ, Shin HK, Park JH. Genistein inhibits insulin-like growth factor-I receptor signaling in HT-29 human colon cancer cells: a possible mechanism of the growth inhibitory effect of Genistein. J Med Food. 2005;8(4):431-8.
91. Wang SD, Chen BC, Kao ST, Liu CJ, Yeh CC. Genistein inhibits tumor invasion by suppressing multiple signal transduction pathways in human hepatocellular carcinoma cells. BMC Complement Altern Med. 2014;14:26.

92. Zhang Y, Li Q, Zhou D, Chen H. Genistein, a soya isoflavone, prevents azoxymethane-induced up-regulation of WNT/betacatenin signalling and reduces colon pre-neoplasia in rats. $\mathrm{Br} \mathrm{J}$ Nutr. 2013;109(1):33-42.

93. Hara Y, Noda A, Miyata S, Minoshima M, Sugiura M, Kojima J, et al. Effects of aged garlic extract on left ventricular diastolic function and fibrosis in a rat hypertension model. Exp Anim. 2013;62(4):305-10.

94. Seo HS, DeNardo DG, Jacquot Y, Laios I, Vidal DS, Zambrana $\mathrm{CR}$, et al. Stimulatory effect of genistein and apigenin on the growth of breast cancer cells correlates with their ability to activate ER alpha. Breast Cancer Res Treat. 2006;99(2):121-34.

95. Spagnuolo C, Russo GL, Orhan IE, Habtemariam S, Daglia M, Sureda A, et al. Genistein and cancer: current status, challenges, and future directions. Adv Nutr. 2015;6(4):408-19.

96. Krajka-Kuzniak V, Paluszczak J, Szaefer H, Baer-Dubowska W. The activation of the Nrf2/ARE pathway in HepG2 hepatoma cells by phytochemicals and subsequent modulation of phase II and antioxidant enzyme expression. J Physiol Biochem. 2015;71(2): 227-38.

97. Wu Y, Feng X, Jin Y, Wu Z, Hankey W, Paisie C, et al. A novel mechanism of indole-3-carbinol effects on breast carcinogenesis involves induction of Cdc25A degradation. Cancer Prev Res (Phila). 2010;3(7):818-28.

98. Ebert B, Seidel A, Lampen A. Phytochemicals induce breast cancer resistance protein in Caco-2 cells and enhance the transport of benzo[a]pyrene-3-sulfate. Toxicol Sci. 2007;96(2):227-36.

99. Traka M, Gasper AV, Melchini A, Bacon JR, Needs PW, Frost V, et al. Broccoli consumption interacts with GSTM1 to perturb oncogenic signalling pathways in the prostate. PLoS ONE. 2008;3(7):1-14.

100. Pappa G, Lichtenberg M, Iori R, Barillari J, Bartsch H, Gerhauser C. Comparison of growth inhibition profiles and mechanisms of apoptosis induction in human colon cancer cell lines by isothiocyanates and indoles from Brassicaceae. Mutat Res. 2006;599(12):76-87.

101. Higdon JV, Delage B, Williams DE, Dashwood RH. Cruciferous vegetables and human cancer risk: epidemiologic evidence and mechanistic basis. Pharmacol Res. 2007;55(3):224-36.

102. Ho JN, Kang ER, Yoon HG, Jeon H, Jun W, Watson RR, et al. Inhibition of premature death by isothiocyanates through immune restoration in LP-BM5 leukemia retrovirus-infected C57BL/6 mice. Biosci Biotechnol Biochem. 2011;75(7):1234-9.

103. Fahey JW, Talalay P. Antioxidant functions of sulforaphane: a potent inducer of Phase II detoxication enzymes. Food Chem Toxicol. 1999;37(9-10):973-9.

104. Lin H, Gao X, Chen G, Sun J, Chu J, Jing K, et al. Indole-3carbinol as inhibitors of glucocorticoid-induced apoptosis in osteoblastic cells through blocking ROS-mediated Nrf2 pathway. Biochem Biophys Res Commun. 2015;460(2):422-7. 